\title{
AlgunS PONTOS DE APROXIMAÇÁo ENTRE A ÉTICA ARISTOTÉLICA E A KANTIANA
}

\author{
Reinaldo Sampaio Pereira ${ }^{1}$
}

\begin{abstract}
RESUMO: Nosso propósito, neste artigo, é aproximar dois modelos éticos distintos, o kantiano e o aristotélico, com o intuito de detectar alguns pontos comuns onde talvez possamos encontrar certo diálogo entre ambos os modelos éticos.
\end{abstract}

PALAVRAS-CHAVE: Ética. Aristóteles. Kant.

Saltam aos olhos, quando se compara a ética aristotélica com a kantiana, acentuadas diferenças entre ambas, por se tratar, sob muitos aspectos, de dois modelos éticos distintos. Contudo, uma aproximação comparativa entre elas pode revelar também pontos comuns. Nossa intenção, neste artigo, é fazer algumas comparaçôes entre ambos esses modelos éticos. Para tal análise, partiremos do início da Fundamentação da Metafísica dos Costumes (doravante Fundamentação) e do início da Ética a Nicômaco (doravante EN).

O primeiro parágrafo da $E N$ e o primeiro parágrafo da Fundamentação começam a revelar dois modelos éticos em muito distintos. No que concerne à $E N$, parece boa estratégia lê-la de uma perspectiva teleológica, tendo como fio condutor um certo telos, um certo fim. Uma vez que a felicidade (eudaimonia), fim último buscado na $E N$, afigura-se como fim último de toda escolha e de toda ação, a análise investigativa na $E N$ seria desenvolvida para dar conta do que é a felicidade e como seria possível alcançá-la. Nesse sentido, vale observar que a argumentação da $E N$ parece estar fortemente amarrada de modo a toda ela ocorrer a partir dos desdobramentos da busca do que é e como é possível alcançar a felicidade. Após apresentar alguns elementos iniciais que, se não são definitórios da felicidade, já nos possibilitam começar a compreender o que ela seria (como a ideia de fim e, sobretudo, de fim último), Aristóteles sugere (no capítulo 5, ainda do primeiro livro da $E N$ ) que a vida feliz a ser buscada pode ser tomada como a

${ }^{1}$ Reinaldo Sampaio Pereira é Professor de História da Filosofia Antiga da UNESP de Marília. Endereço eletrônico: reinaldo@marilia.unesp.br. 
vida virtuosa e/ou também como a vida contemplativa. A vida virtuosa parece ser a grande candidata à vida feliz própria ao homem. Aristóteles dedica praticamente metade da $E N$ à investigaçáo a respeito da virtude ${ }^{2}$. As investigaçóes acerca da deliberação, da escolha, da disposição etc. são realizadas para atender às exigências dadas pela investigação sobre a virtude. Após o término da análise da virtude, os demais objetos investigados, como o prazer, a figura do acrático, a investigação a propósito da amizade ou, no final do texto, a análise da vida contemplativa, possibilitam certa compreensão do que é e como alcançar o fim último da ética, qual seja, a felicidade.

Já na abertura da Fundamentação (texto no qual se procura determinar o princípio supremo da moralidade), Kant, negando um modelo ético como o aristotélico, descarta a possibilidade de algo ser um bem em si (seja esse algo a inteligência, uma virtude cardinal grega, como a coragem, ou até mesmo a felicidade), exceto uma boa vontade. Essa formulação, em um primeiro momento negativa e extremamente forte, começa a demonstrar como o modelo ético kantiano se opóe, em boa medida, ao modelo aristotélico. Essa formulação inicial da Fundamentação toca, de certo modo, em duas questóes muito significativas da $E N$. Para observá-las, ainda que muito rapidamente, inicialmente lembremos uma célebre passagem do cap. 6 do livro I da $E N$ (1096a23), onde, em uma estratégia similar à traçada na sua Metafísica, em que é negada a multiplicidade de modos de dizer o ser, Aristóteles nega, na busca investigativa acerca do que é o bem, a unidade genérica deste (do bem), sustentando que, à semelhança do que afirmou a respeito do ser, o bem é dito de múltiplos modos. O bem referente à substância seria Deus ou a inteligência (nous), o referente à qualidade, às virtudes etc. Sendo assim, no concernente aos diversos modos de dizer o bem, parece lícito afirmar que, em Aristóteles, sendo as demais categorias ditas em relação à substancialidade, elas são ditas, de certo modo, quanto à inteligência, o que torna a atividade de certa parte racional da alma um bem.

Contudo, disso não se segue que toda ação resultante de uma certa operação racional seja um bem. A operação da parte calculativa da alma pode estar a serviço de uma ação considerada moralmente reprovável. Aristóteles rechaça um modelo ético intelectualista, segundo o qual o conhecimento da boa ação conduz necessariamente à boa açáo, que, portanto, só agiria mal, do ponto de vista ético, aquele que desconheceria como agir bem. Em Aristóteles, é possível que o agente moral faça bom cálculo do que deve fazer para que a sua ação seja moralmente boa e, contudo, não consiga agir bem, como pode ocorrer com o

\footnotetext{
${ }^{2}$ No último capítulo do livro I (cap. 13), Aristóteles inicia a investigação sobre o que ele nomeia virtude ética, investigação essa que irá se estender até o final do livro V. No livro VI, dedica-se à análise da virtude dianoética.
} 
acrático (incontinente). Nesse sentido, Aristóteles distingue o phronimos (aquele que possui boa capacidade calculativa para agir bem) daquele que é habilidoso para tais cálculos, mas sem que, necessariamente, consiga agir segundo os seus cálculos. O phronimos possui uma boa disposição (hexis), a qual o inclina a agir bem. Como visto, em Aristóteles, diferentemente de um certo modelo intelectualista, é possível a capacidade calculativa da razão náo estar a serviço da boa ação. Certa operação da razão, por si só, não garante uma boa ação, um bem. Em Aristóteles, nem mesmo há uma razão que, por si só, seja capaz de engendrar açôes. Nesse sentido, em ENVI 1139a35, é afirmado que "[...] o pensamento, por si só, nada move”. Em Aristóteles, o engendramento de uma açáo pressupóe certa operação do desejo, o qual consiste, na análise psicológica da sua ética, em móvel das açôes, e o desejo é, em boa medida, engendrado por uma disposição (hexis). É possível ao agente, por um lado, ter boa capacidade calculativa para agir e, por outro lado, ter disposição viciosa, a qual faz com que ele tenha normalmente o desejo de agir viciosamente. Assim, a capacidade racional calculativa não garante o engendramento de boas açóes. Ainda que o modelo ético aristotélico e o kantiano sejam em muito distintos, ambos os autores parecem sustentar que certa capacidade racional nâo conduz necessariamente a um bem. Kant apresenta o discernimento como náo sendo necessariamente bom, se não acompanhado de uma boa vontade. Em Aristóteles, a capacidade racional calculativa, quando não acompanhada de uma boa disposição, pode engendrar más açôes ${ }^{3}$.

No que tange à felicidade, não obstante haja diferenças entre as concepçôes kantiana e aristotélica de felicidade, parece haver também semelhanças entre ambas. Em Kant, a felicidade parece ser algo indeterminado, pois, sendo impossível dizer o que ela é. Nesse sentido, apesar do desejo do homem em buscála, aquele que a busca, parece sugerir Kant, não pode precisar o que exatamente está buscando, o que exatamente deseja e quer. Já em Aristóteles, há a busca de uma certa compreensão do que é a felicidade. Evidentemente, muitos problemas se apresentam na busca do que ela seja, como o problema relativo à discussão sobre qual vida poderia ser propriamente tomada como a vida feliz, se a vida contemplativa ou a vida virtuosa. Mas tais dificuldades náo impedem Aristóteles de propor que se deve não apenas buscar a felicidade, mas também sugerir que esta se apresenta (e aqui reside uma grande diferença do modelo aristotélico em relação ao kantiano) como norte para as açôes humanas e, de certo modo, como fio condutor para a análise ética empreendida na EN. Em Aristóteles, a felicidade

\footnotetext{
${ }^{3}$ Em relação a Kant, não estamos aqui fazendo referência a uma razão pura que, sendo capaz de principiar uma ação por respeito à lei, é prática, engendradora da ação moral. Aqui, aludimos a uma certa capacidade racional que, a partir de dados da experiência, é capaz de, mediante imperativos hipotéticos (e não categóricos), orientar o agente para que ele possa realizar açóes que o conduzam à felicidade.
} 
não é apenas um bem, mas o sumo bem, fim último a ser buscado no domínio prático (portanto, esse é o fim não apenas na Ética, mas também na Política). A ética aristotélica é teleológica, e o telos, o fim buscado, é justamente a felicidade. Aristóteles examina o bem, a ação moralmente boa e a vida virtuosa a partir do fim último, bem supremo, a partir da felicidade. Já Kant, ainda no primeiro parágrafo da Fundamentação, faz uma afirmação que aparentaria escandalosa no contexto da $E N$, a de que sequer a felicidade pode ser tomada como incondicionalmente boa, sem uma boa vontade. Em Kant, a ação que tem como motor qualquer dado sensível não pode ser moralmente boa. A ação moralmente boa seria engendrada exclusivamente pela lei moral, sem qualquer intervenção externa. Se, em Kant, a felicidade é buscada pelos homens, por conseguinte, podendo ser tomada como fim que, de algum modo, pode orientar as açóes do agente a partir de imperativos hipotéticos, agir buscando a felicidade e não apenas por respeito à lei moral faz da ação realizada não uma ação moralmente boa.

Para Kant, como visto, nada pode ser tomado como bom incondicionalmente, exceto uma boa vontade. Cabe então a Kant examinar o que torna uma vontade boa. De acordo com Kant, o que torna uma vontade boa não seriam os seus resultados, pois, se assim fosse, a felicidade poderia ser tomada como boa, se houvesse, em Kant, uma boa vontade que tivesse como fim a promoção da felicidade. Para começar a dar conta do que seria a vontade boa em si, a estratégia adotada por Kant parece ser a de oferecer a compreensão do que seria a boa vontade a partir do conceito de dever. O dever é a necessidade de cumprir uma ação por respeito à lei. $\mathrm{O}$ respeito não se dá com respeito a uma inclinação, mas em relação a lei em si, que expressa, em uma das suas formulaçôes: devo me portar de modo tal que eu possa querer que a minha máxima possa se converter em lei universal. Kant, dessa maneira, distingue a ação que é conforme ao dever daquela que é por dever. No concernente à conformidade ou não da ação com o dever, é feita, na primeira seção da Fundamentação, a distinção entre alguns tipos de açôes. Um primeiro tipo seria a ação contrária ao dever, evidentemente não moralmente boa. Na sequência, Kant distingue as açôes conforme ao dever das açóes por dever. No que diz respeito às açôes conforme ao dever: distingue a ação conforme ao dever em que o sujeito é levado a ela por uma inclinação imediata, tendo sido a ação praticada por outro motivo que o respeito à lei, como a ação praticada por motivo egoísta, da ação por dever, por puro respeito à lei, sendo o seu móvel exclusivo a razão pura prática. A ação moral deve ser realizada não por inclinação, mas por dever. A açáo conforme ao dever, mas não por dever, pode ser realizada por uma inclinação, ao passo que a açáo por dever (portanto, também conforme ao dever) é motivada exclusivamente pelo respeito à lei moral. 
A ética kantiana apresenta um princípio a priori, a lei moral, que possibilita determinar se uma ação possui ou não valor moral, ainda que não seja fácil detectar se uma ação foi realizada tendo-o exclusivamente como móvel, sendo difícil, pois, detectar a realização de uma ação que tenha valor moral. Essa dificuldade não é dada pela inexistência de um princípio determinante a priori de como agir bem ou pela determinação prévia do modo como o princípio deve se converter em móvel da ação no agente, mas justamente pela impossibilidade de se detectar se o princípio se converte ou não em móvel exclusivo da ação, condição necessária para que ela receba valor moral. Aqui reside uma outra grande diferença entre o modelo ético kantiano e o modelo aristotélico: enquanto há, em Kant, uma regra que possibilita determinar a priori uma ação que possui valor moral, em Aristóteles não há tal regra. Não havendo tal princípio a priori em Aristóteles, sua estratégia é examinar como é possível agir bem recorrendo à figura do phronimos (prudente). Agir bem, em cada circunstância, é agir como agiria, na mesma circunstância, o phronimos. Apresenta-se aqui um problema de fundamentação na ética aristotélica, inexistente na kantiana, qual seja este problema: se, por um lado, Aristóteles recorre à figura do phronimos para tornar possível a determinação da boa ação, por outro lado, o phronimos é apresentado como aquele que age bem. O phronimos é o que permite a determinação da boa ação, e esta se afigura como condição necessária para definir o phronimos. Inexiste, assim, um sólido fundamento, seja para determinar alguém como phronimos, seja para determinar uma ação como sendo boa.

Em Aristóteles, não encontramos um princípio determinante a priori das boas açóes. Todavia, a não existência de um princípio determinante a priori de uma boa ação não implica a inexistência de uma certa regra, a qual deve ser seguida se se quer agir bem. Em Aristóteles, uma ação só pode ser considerada moralmente boa, se ela for concorde com o justo-meio. O justo-meio não consiste em uma média aritmética (assim como o 3 é o meio termo entre o 2 e o 4), pois ele depende tanto do objeto, o qual varia caso a caso, quanto daquele que age, não sendo o justomeio o mesmo para todos os indivíduos com relação ao mesmo objeto. No que concerne à dependência do objeto para a determinação do justo-meio, vale observar que este é por vezes mais oposto a um dos vícios (o correspondente ao excesso ou à falta), não sendo necessariamente equidistante dos mesmos. Em alguns casos, a falta é mais oposta ao justo-meio, em outros, o excesso. A covardia, por exemplo, que é um vício de deficiência, é mais oposta à coragem que a temeridade, que é um vício de excesso; mas a intemperança (excesso) é mais oposta à temperança que a insensibilidade (falta) (EN II 1108b36). Não apenas do objeto depende certa maleabilidade do justo-meio, mas também do agente da ação, não consistindo o justo-meio, por conseguinte, necessariamente em o mesmo para todos, porém, variando de indivíduo para indivíduo, assim como a boa quantidade de alimento, 
que necessariamente se situa entre o excesso e a falta, varia de pessoa para pessoa, dependendo das necessidades de cada um (EN II 1106a37). A boa quantidade de alimento para um atleta pode ser diferente da boa quantidade de alimento para aquele que está iniciando as suas atividades atléticas (1106b4). Em Aristóteles, para uma ação ser considerada moralmente boa, ela deve atender a um justo-meio. Mas esse princípio formal da ação moralmente boa, o justo-meio, não possibilita a determinação a priori da boa ação, uma vez que o justo-meio pode variar caso a caso, podendo a ação ser detectada como moralmente boa apenas no momento em que ela é realizada.

Em Kant, o imperativo categórico apresenta-se como princípio necessário e suficiente para a determinação de uma ação moralmente boa. Em Aristóteles, ainda que seja necessário a ação atender ao justo-meio, para ser considerada moralmente boa, o conhecimento de tal necessidade não é suficiente para fazer com que o agente possa agir moralmente bem, atendendo ao justo-meio. Contudo, como explicar a insuficiência do justo-meio, na determinação de uma ação moralmente boa? A determinação da boa ação só pode se dar, em Aristóteles, caso a caso, pois a ação é sempre particular, como afirmado em diversas passagens do corpus, como em EN III 1110b7, ou então em Met., onde o Estagirita chega a afirmar que na vida prática têm mais êxito os experientes (portanto, os que têm o conhecimento dos particulares) que os que possuem o conhecimento teórico (universal). Nesse sentido, ilustra sustentando que não é o homem (universal) que é curado pelo médico, exceto acidentalmente, mas Cálias, Sócrates ou outro homem particular qualquer (Met. 981a13). Assim como o médico cura o indivíduo e não o homem (universal), a determinação da boa ação só se dá individualmente e em cada contexto particular. De modo similar ao que ocorre com a técnica: cabe ao phronimos determinar, caso a caso, como agir bem (atendendo ao justo-meio). Dessa maneira, ele se afigura, de certo modo, como padrão e medida de como se deve agir. No entanto, se o phronimos se converte em regra para ajuizar se uma certa ação é boa ou má, o que o torna apto a aquilatar toda a classe de açóes com acerto? O que lhe confere a capacidade de ajuizar sobre o certo e o errado, na esfera prática?

O phronimos é aquele que age habitualmente atendendo ao justo-meio. O hábito lhe confere experiência na realização das boas açóes, por conseguinte, capacidade de apreender o justo-meio em cada caso particular. Se não há um critério universal determinante a priori das boas açóes, sendo estas, de certo modo, determinadas em cada caso particular, então é necessário que aquele que é mais apto para determinar em cada caso qual a melhor açáo tenha experiência para fazê-lo. Ademais, Aristóteles necessita de um elemento adicional para pensar como é possível ao agente moral inclinar-se para agir segundo o justo-meio ou mesmo evitar agir conforme as suas inclinaçóes, quando estas não são concordes com o 
justo-meio (como no caso do continente). Esse elemento adicional próprio ao phronimos é a boa disposição. Mas, como é possível ao agente moral adquirir uma boa disposiçáo? Em uma equaçáo de certo modo reducionista, mas relevante para o nosso argumento: se nos reportamos a Met. 1047b31, onde Aristóteles distingue as potências congênitas, como os sentidos, daquelas adquiridas pela prática, como a de tocar flauta, podemos observar que o que possibilita a aquisição da segunda é um exercício prévio. De modo similar, é pela prática de ações virtuosas que se desenvolve a capacidade de agir virtuosamente. A atividade gera a potencialidade que lhe é afim. Isso não implica que o agente moral não possua qualquer potencialidade para agir virtuosamente, antes de realizar suas primeiras açóes virtuosas. Em Aristóteles, algo só vem a ser em ato se anteriormente (do ponto de vista cronológico) era em potência.

Entretanto, como ao agente moral é possível começar a agir virtuosamente para desenvolver uma disposição virtuosa, se ele ainda não é virtuoso, mas apenas possui potencialidade para vir a se tornar virtuoso, ao formar uma boa disposição com a prática de açóes virtuosas? Como estratégia para contornar tal aporia, uma possibilidade é resgatar a distinção kantiana feita na Fundamentação entre ação conforme ao dever e ação realizada por dever, para pensar a distinção aristotélica entre ação realizada conforme a virtude e ação propriamente virtuosa. Considerando essa distinção aristotélica, há a possibilidade de o agente moral agir conforme à virtude acidentalmente ou sob a orientação de outrem, assim como alguém que age bem porque foi aconselhado ou obrigado a agir de tal modo. Para que a ação seja não apenas conforme a virtude, mas também virtuosa, são necessárias algumas condiçôes: o agente deve realizar a ação com conhecimento das suas causas e consequências, e a açáo deve ser realizada de modo deliberado, com o agente escolhendo-a por ela mesma. Ademais, a ação deve ser engendrada por uma disposição fixa e permanente (EN II 1105a29). Uma única ação feita como a faria um homem virtuoso não é suficiente para caracterizar alguém virtuoso, nem mesmo para designar como virtuosa a açáo (ENI 1098a18), a qual, a rigor, implica um estado habitual virtuoso ${ }^{4}$.

Uma ação conforme ao dever, porém, que não tenha sido realizada por respeito à lei moral, e sim por alguma inclinação subjetiva, não possui, em Kant, valor moral, assim como, guardadas as devidas diferenças entre a ética kantiana e

\footnotetext{
${ }^{4}$ Observemos que a estratégia de encontrar em Aristóteles uma distinção equivalente à distinção kantiana entre ação por dever e ação conforme ao dever talvez não seja feliz, do ponto de vista da História da Filosofia, na medida em que talvez tal distinção não exista, de fato, na $E N$, podendo levar a implicaçōes que descaracterizam a argumentação aristotélica. Mas ela parece boa do ponto de vista filosófico, uma vez que permite ao menos uma aparente boa interpretação no concernente à passagem da pré-formação da disposição virtuosa para a ação propriamente virtuosa, sendo tal passagem intermediada pela formação da boa disposição.
} 
a aristotélica, em Aristóteles, a ação pode ser concorde com o modo como agiria o phronimos e, no entanto, não ser propriamente uma boa ação. A ação passível de receber valor moral, em Kant, é aquela realizada náo apenas conforme ao dever, mas também por dever. Recebe valor moral a ação que é motivada exclusiva e obrigatoriamente pela lei moral. De certa perspectiva semelhante, a ação moralmente boa, em Aristóteles, é aquela realizada não apenas como a realizaria o phronimos, o qual possui uma boa disposição, mas ela deve ser motivada por uma boa disposição do agente. Valendo-nos de uma estratégia anteriormente por nós utilizada para pensar se a lei moral (em Kant) e o princípio segundo o qual se deve agir segundo o justo-meio (em Aristóteles) são suficientes para determinar se uma ação é moralmente boa: em Kant, ser concorde com a ação realizada como por respeito à lei moral é condição necessária, mas não suficiente, para a ação receber valor moral, assim como, de modo semelhante, em Aristóteles, ser concorde com o modo como agiria o phronimos, em determinada situação, também é condição necessária, mas não suficiente, para, a rigor, caracterizar uma ação como boa.

Em Kant, há um único modo de agir moralmente bem, qual seja, por respeito à lei. Se considerarmos o termo "necessário" segundo uma das acepçóes como ele é apresentado em Metafísica 5, a saber, como sendo "[...] necessário aquilo que não pode ser de outro modo" (1015a34), parece lícito afirmar que a ação moralmente boa, em Kant, é aquela que necessariamente é realizada tendo como móvel exclusivo a lei moral. De modo similar, em Aristóteles, se a boa ação é aquela que atende ao justo-meio, e este pode ser apenas um em um dado contexto (consistindo em vícios as demais possibilidades de açóes no mesmo contexto), segue-se que a boa ação é necessariamente uma em cada circunstância. Tanto em Aristóteles como em Kant há um certo domínio da necessidade quando se examina a esfera ética nos dois autores da perspectiva de como deve ser uma ação, em cada contexto, para ser considerada moralmente boa, em Aristóteles, ou passível de receber valor moral, em Kant; contudo, tal domínio necessário na ética de ambos não implica no esvaziamento da possibilidade de escolha na esfera ética, não implica um necessitarismo prático. O domínio da contingência é resguardado em ambos os autores, quando se examina a esfera ética da perspectiva da multiplicidade de possibilidades de açóes do agente. Por mais que, em Aristóteles, para agir bem, haja a necessidade de agir atendendo ao justo-meio, cabe ao agente moral muitas vezes, escolher se irá agir de certo modo ou de outro, se a sua ação será moralmente boa ou não. De maneira similar, em Kant, muito embora a lei moral imprima o caráter da necessidade ao agente, se ele agir moralmente bem, isso não acarreta o esvaziamento da possibilidade de escolha no momento de agir, uma vez que cabe a ele ou agir exclusivamente pelo respeito ao imperativo categórico ou então atendendo a uma máxima subjetiva. 
Por fim, observemos que, no que concerne ao phronimos, tão caro à ética aristotélica, ele se apresenta no modelo ético do Estagirita como condição necessária para detectar a boa ação, a ação virtuosa e, consequentemente, para o agente moral alcançar o fim último da ética, a saber, a felicidade, se esta apenas for possível mediante uma vida virtuosa. Também em Kant é resguardada a importância do phronimos para alcançar a felicidade. Todavia, uma vez que o phronimos age segundo imperativos hipotéticos e não segundo o imperativo categórico, sua ação não recebe valor moral. Kant não atribui ao phronimos a função de determinar a ação passível de receber valor moral. No modelo ético kantiano, conforme o qual, para uma ação ter valor moral, ela náo pode ser motivada por qualquer fim para o qual se inclina o agente no momento de agir, pulveriza-se a funçáo do phronimos enquanto aquele que representaria o critério de determinação da ação moral. Ainda que Kant resguarde para o domínio dos imperativos hipotéticos a felicidade, portanto, náo podendo esta se afigurar como guia para a ação moral, rechaçando o phronimos como aquele que age bem, por outro lado, como observa Aubenque, "[...] o homem, na vida concreta, não se determina apenas e nem freqüentemente segundo o imperativo da moralidade, mas segundo os imperativos 'técnicos' da habilidade e os imperativos 'pragmáticos' da prudência" ${ }^{5}$. Dessa perspectiva, observemos novamente que a importância da figura do phronimos, de certo modo, é resguardada em Kant, ainda que não no domínio ético. Se Kant propóe um novo modelo ético em relação ao modelo aristotélico, necessitando, para isso, rechaçar em grande medida Aristóteles, por outro lado, ele não o faz sem promover certo diálogo com a ética aristotélica, diálogo esse acerca de estratégicos elementos da ética aristotélica.

PEREIRA, Reinaldo Sampaio. Some common things between the aristotelian and kantian ethics. Trans/Form/Ação, Marília, v. 34, n.3, p. 31-40, 2011.

ABSTRACT: Our purpose in this paper is to bring together two different ethical models, the kantian and aristotelian, in order to detect some common things where we may find some dialogue between the two ethical models.

KEYWORDS: Ethics. Aristotle. Kant.

${ }^{5}$ Cf. AUBENQUE, P. A Prudência em Aristóteles. São Paulo: Discurso Editorial, 2003, p. 298. O artigo La prudence chez Kant foi publicado na Revue de Métaphysique et la moral, LXXX, 156-82, em 1975. Esse artigo foi posteriormente incorporado como apêndice na terceira edição do seu célebre livro $L a$ prudence chez Aristote, publicada no Brasil pela Discurso Editorial, em 2003. 
PEREIRA, R. S

\section{REFERÊNCIAS}

ARISTÓTELES. Nicomachean Ethics. London: Loeb Classical Library, 1990.

AUBENQUE, P. A Prudência em Aristóteles. São Paulo: Discurso Editorial, , 2003.

KANT, I. Fundamentação da Metafísica dos Costumes. Tradução de Paulo Quintela. , São Paulo: Abril Cultural, 1974 (Col. Os Pensadores).

recebido em: 09.03.2011

aprovado em: 29.07.2011 